\title{
Identification of fatty acid profile, lipid characterization and nutritional status of Clarias batrachus
}

\author{
Rafiquel Islam ${ }^{1 *}$, Liton Kumar Mondol', Liton Sheikh', Sk. Shahinur Rahman², Mominul Islam² and Atiqur Rahman \\ *Correspondence: rafiq.acct@gmail.com \\ 'Department of Applied Chemistry and Chemical Technology, Islamic University, Kushtia, Bangladesh. \\ ${ }^{2}$ Department of Applied Nutrition and Food Technology, Islamic University, Kushtia, Bangladesh.
}

\begin{abstract}
The present study was carried out to characterize the lipids isolated from Clarias batrachus and to analyze the nutrient contents of these fishes. The specific gravity $\left(0.87\right.$ at $\left.30^{\circ} \mathrm{C}\right)$, refractive index $\left(5.19\right.$ at $\left.30^{\circ} \mathrm{C}\right)$, co-efficient of viscosity $(448.26)$ were measured. Besides, the quantitative analysis of acid value (1.93), percent of free fatty acids (0.97\%), saponification value (179.88), saponification equivalent (311.87), iodine value (53.93), peroxide value (43.63), ester value (177.95), unsaponificable matter (1.96\%), acetyl value (16.09), reichert-meissel value (3.13), cholesterol (15.46\%) were evaluated. Likewise, carbohydrate, protein and lipids were $6.26,14.14$ and $6.91 \%$ respectively. Moisture contents were $78 \%$ but ashes were $(0.1 \%)$. Further, the mineral studied as calcium, phosphorus and iron were $210.10,70.05$ and $7.06 \mathrm{mg} / \mathrm{kg}$ respectively, whereas zinc contents were trace amount. The fatty acids profile of $C$. batrachus was identified as lauric acid (2.6\%), palmitic acid (37.41\%), oleic acid (49.1\%) and stearic acid (3.6\%) arachidic acid (3.04\%) and behanic acid (4.21\%) respectively.
\end{abstract}

Keywords: Clarias batrachus, lipids, fatty acids, nutrients

\section{Introduction}

Bangladesh is a country with hundreds of rivers and ponds and is notable for being a fish-loving nation where fishes play an important role in the Bangladeshi diet, constituting the main and often irreplaceable animal source food in poor rural households. Most of the people in the developing countries are dependent on fish as a source of animal protein. It has been estimated that about $80 \%$ of the animal protein in the diet of the people of Bangladesh comes from fish alone [1]. Clarias batrachus, the walking catfish, has an elongate body that is broader at the head, tapering toward the tail. It is readily recognizable as a catfish with four pairs of barbels (whiskers) and fleshy, papillated lips. The teeth are villiform (small and bristle-like), occurring in patches on the jaw and palate [2]. The eyes are small. The pectoral spines are large and robust and finely serrate along the margins. There is no dorsal spine. The dorsal fin is continuous and extends along the back twothirds of the length of the body. The dorsal, caudal, and anal fins together form a near-continuous margin; the caudal fin is rounded and not eel-like though it is occasionally fused with the other fins [3]. In Bangladesh, there is a traditional concept that during pregnancy and lactation period and for the convalescent of the patients, C.batrachus is helpful for blood formation. In India, it is also used as a medicinal fish for various physiological condition such as pregnant and lactating mother, children, anemic and malnourished persons etc. [4].

C. batrachus contain polyunsaturated fatty acids (PUFA), which play important roles in cardiovascular system to reduce the risk of heart attack. Fish yield high amounts of proteins which is basic element of diet. It can be broken down into amino acids, which are essential for the growth and repair of body tissue. But some proteins are incomplete and must be supplemented with other protein foods, fish proteins are completed. A four-ounce serving can contain from thirty to fifty percent of the body's daily requirement of protein. Fishes are also a valuable source of vitamins, which are necessary for the body's functions. Fish liver oil is an exceptional source of vitamins $A$ and $D$. Vitamin $A$ is necessary for healthy skin and development of bones. Vitamin D plays an important part in the body's use of calcium, a mineral vital for sound teeth and bones. Fat fish in particular are a prime source of vitamin D. All fish contain several of the B complex vitamins necessary for many of the body's processes, especially digestion and the nervous system. These are essential for healthy skin, and the normal operation of the liver and kidneys. They also can reduce the cholesterol level in blood, decreasing the chances of heart disease. Lack of the proper amount of vitamins can lead to vitamin deficiency diseases [5].

There are three conditions for which fish oil, as well as other sources high in omega-3 is highly recommended: hypertriglyceridemia, secondary cardiovascular disease prevention and high blood pressure. There are other reasons to supplement ones' diet with sources of omega-3 (like fish oil), however, there can be side effects. The side effects increase the risk of bleeding. This fish is well known to the native physicians of some parts of Bangladesh for its recognized usefulness. In view of the recognized usefulness of this fish species, the present work has been under taken and the results have been 
reported in this communication.

\section{Materials and methods \\ Collection of fish sample}

Fresh water 10 fish (Clarias batrachus) samples were collected from Municipal fish Market, Kushtia, Bangladesh at the time of Late Autumn. The average weight of each piece of fish was $300 \mathrm{~g}$ and the age of $C$. batrachus was approximately 3.5 years.

\section{Extraction of lipid using organic solvents}

After collection, $50 \mathrm{~g}$ fish fillet was cleansed by discarding their bones, liver, stomach and viscera. Then it was transferred to a volumetric flask. Then lipids were extracted by solvent extraction method using chloroform-methanol solvent [6].

\section{Characterization of lipid of Clarias batrachus}

After extraction, the solvent was removed from the lipid at low temperature (to prevent oxidation) with the help of a rotary vacuum evaporator. The lipid was stored at $4^{\circ} \mathrm{C}$ in the presence of an inert gas until analyzed. The physico-chemical characterizations were determined using standard methods [7].

\section{Determination of Fatty acids profile}

Preparation of the methyl ester mixture from the lipid The lipid $(5 \mathrm{~g})$ was taken in a round bottom flask $(125 \mathrm{ml})$ and saponified with alcoholic potassium hydroxide solution (50 $\mathrm{ml}$ ). The mixture was then refluxed for 45 minutes on a water bath until it became clear. The reaction mixture was allowed to cool and then neutralized with $\mathrm{HCl}(5 \mathrm{~N})$. Alcohol was removed from the neutralized solution by evaporation over a steam bath. $25 \mathrm{ml}$ water was added to this alcohol free solution and $\mathrm{pH}$ of the solution was adjusted by adding concentrated $\mathrm{HCl}$. The acidified aqueous mixture was then extracted with $20 \mathrm{ml}$ ether in a separating funnel and the extraction was repeated for three times. The combined ether extract was washed with water in order to remove any adhering $\mathrm{HCl}$. Ether was then removed from the extract to give the fatty acid mixture. The fatty acid mixture was then esterified with methanolic solution of sulfuric acid $(0.25 \mathrm{M}, 5 \mathrm{ml} / \mathrm{g}$ acid). After esterification, the mixture was dissolved in ether $(25 \mathrm{ml})$ in a separating funnel and washed with dilute sodium carbonate solution until the effervescence ceased. It was then washed with water, dried over anhydrous $\mathrm{Na}_{2} \mathrm{SO}_{4}$ and finally ether was removed to give methyl ester mixture $[8,9]$.

Gas liquid chromatographic examination of methyl esters The experiment was carried out with a "PUE UNICAM" $4500 \mathrm{U}$ model gas chromatograph equipped with a flame ionization detector. A glass coiled column ( $3 \mathrm{~mm}$, I.D. $2.1 \mathrm{~m}$ ) packed with 70-100 mesh chromosorb after impregnating it with $10 \%$ diethylene glycol succinate was used for the regular packed column GLC. The temperature programming in the oven was from $130^{\circ} \mathrm{C}$ to $230^{\circ} \mathrm{C}$ with the rate of rising $4^{\circ} \mathrm{C}$ per minute. The oven, injector and detector temperature were 190, 200 and $205^{\circ} \mathrm{C}$ respectively with a nitrogen carrier gas flow rate $30 \mathrm{ml} / \mathrm{min}$. The speed of the chromatogram was at $0.5 \mathrm{~cm} /$ min [10]. The fatty acids in the mixture were identified by comparing its relative retention volume. The area of each chromatogram peak was determined by multiplying the height of the peak by the width of the peak at one-half of the height. The percentage of fatty acid contributing to each peak was calculated and the results have been computed in the Table 3.

\section{Nutritional status of Clarias batrachus Estimation of minerals by Atomic Absorption Spectrophotometer (AAS)}

For the estimation of the trace elements (Ca, P, Fe and $\mathrm{Zn})$ of Clarias batrachus, the chemical analyses of fish were performed with flame atomic absorption spectrophotometer. The technique involved the following steps:

\section{Preparation of the standard solution}

The stock standard solutions of $100 \mathrm{ppm}$ were prepared from analytical grade reagents of $\mathrm{Ca}, \mathrm{P} \mathrm{Fe}$ and $\mathrm{Zn}$ salt with distilled demonized water. The stock standard solution were preserved in clean polythene bottles and kept in a refrigerator. Standard solutions of these metal ions were prepared by suitable dilution of the stock standard solution. Dilution was made freshly with distilled demonized water.

\section{Analysis of fish sample}

The sample of fish were diluted to a known volume and analyzed by a flame atomic absorption spectrophotometer (Flame AAS). The samples were analyzed against standard solution of each element. A reagent blank was also maintained, and the absorption due to reagent was subtracted. All the glasses were Pyrex and were cleaned before use with detergent, 1:1 $\mathrm{HNO}_{3}$ and demonized water to avoid any contamination. All the reagents and chemicals were of analytical grade, reagents were prepared with distilled deionized water. The water was prepared by passing distilled water through a mixed-bed ion-exchange resin column. Samples were subsequently analyzed for trace elements by "AAS-680"Atomic Absorption / Flame Emission spectrophotometer (Shimadzu, Japan). A single hollow cathode lamp for each element was used with an air-acetylene and nitrous-oxide-acetylene $[11,12]$.

\section{Statistical analysis}

The identification of fatty acid profile, physico-chemical characterization the lipids and nutrients of Clarias batrachus were analyzed. Each experiment was run in triplicate, and mean values were calculated.

\section{Results and discussion Characterization of lipid of Clarias batrachus}

The lipids from were extracted by solvent extraction process using chloform- methanol as an extracting solvent. It was 
Islam et al. Nutritional Science and Food Technology 2013,

Table 1. Physical constants of the lipids of Clarias batrachus.

\begin{tabular}{lc}
\hline Physical constant & Clarias batrachus \\
\hline Specific gravity $\left(30^{\circ} \mathrm{C}\right)$ & 0.87 \\
Refractive index $\left(30^{\circ} \mathrm{C}\right)$ & 5.19 \\
Co-efficient of viscosity & 448.26 \\
\hline
\end{tabular}

Values are given as mean of triplicate experiments.

Table 2. Chemical constants of the lipids of Clarias batrachus.

\begin{tabular}{lc}
\hline Chemical constants & Clarias batrachus \\
\hline Acid value & 1.93 \\
Percentage of free fatty acid & 0.97 \\
Saponification value & 179.88 \\
Saponification equivalent & 311.87 \\
Iodine value & 53.93 \\
Peroxide value & 43.63 \\
Ester value & 177.95 \\
Unsaponificable matter (\%) & 1.96 \\
Acetyl value & 16.09 \\
Reichert-Meissel value & 3.13 \\
Cholesterol value (\%) & $15.46 \%$ \\
\hline
\end{tabular}

Values are given as mean of triplicate experiments.

Table 3. Fatty acid percentages derived from methyl ester mixture (by GLC analysis).

\begin{tabular}{llll}
\hline Ret. time & Area & $\begin{array}{l}\text { Name of fatty } \\
\text { Acid }\end{array}$ & $\begin{array}{l}\text { Rel.\% in Clarias } \\
\text { batrachus }\end{array}$ \\
\hline 9.65 & 118 & Lauric Acid & 2.60 \\
12.94 & 1694 & Palmitic Acid & 37.41 \\
15.89 & 2223 & Oleic Acid & 49.10 \\
16.34 & 163 & Stearic Acid & 3.60 \\
19.00 & 138 & Arachidic acid & 3.04 \\
21.91 & 191 & Behanic acid & 4.21 \\
\hline
\end{tabular}

Ret. time means Retention time; Rel. \% means Relative percentages.

found that the fish contained lipid of $6.91 \%$. The previous report shows that the total lipid percent of African catfish (Clarias batrachus) for ovary and testis was $19.06 \%$ and $19.45 \%$, respectively. [13]. The physical and chemical characteristics of the lipids vary between certain limits and due to a small variation, they are considered to be constants. Although the chemical constants are more important to characterize the lipid, but physical constants are also often capable of giving valuable information (Table 1).

The specific gravity of lipid C. batrachus presently examined from the different stages was 0.87 at $30^{\circ} \mathrm{C}$. The refractive index of oils or fats varies somewhat widely and is chiefly governed by the proportion and degree of unsaturated matter present. It was found that the R.I. of the oils of C. batrachus was 5.19 and Besides, Co-efficient of viscosity was 448.26 [14] (Table 1).

The percentages of free fatty acids (above 1.5\%) are a determination or indication of unsuitability of the lipid for edible purpose [15]. The free fatty acids were found in the ranges of $0.97 \%$ which were lower than the above ranges. So, these lipids might be suitable for edible purpose. Besides, the iodine value gives an estimation of the degree of unsaturation. In the present investigation, the lipids contained higher amount of unsaturated fatty acid as the iodine value were 53.93. The unsaponifiable matter amounting to $0.45-2.0 \%$ represents a mixture of several lipid classes e.g., sterols, tocopherols, hydrocarbons, higher aliphatic and terpenoid alcohol. The unsaponifiable matters in the lipids of were found to be $1.96 \%$ which indicated that the lipid contained higher amount of sterols, tocopheros, hydrocarbons etc. Saponification equivalent is directly proportional to the average chain length of fatty acid present. Fats or oils consisting largely of $\mathrm{C}_{18}$ fatty acids along with some myristic, palmitic acids, a little unsaponifiable matter and a low free acidify generally have a saponification equivalent around 290.80; higher value indicates the presence of appreciable quantity of higher acids [16]. The saponification equivalents of $C$. batrachus were 311.87 which clearly indicated that the lipid contained mainly fatty acids of $C_{18}$ molecular weight along with some palmitic acid. The reichert-meissl (R.M) value represents the amount of volatile and water soluble acids components. The R.M value of $C$. batrachus was 3.13 which indicated that it presents the higher amounts of volatile and water soluble acids. On the other hand, the lipid contains higher amounts of ester because the ester value of $C$. batrachus was 177.95. Also, the acetyl value and cholesterol value were 16.09 and $15.46 \%$ respectively (Table 2 ).

In Figure 1, the fatty acid analysis of the lipid was carried out by GLC after trans-esterification of the glycerides to their methyl esters. The stationary phase used in the column was the polar polyester 10\% DEGS (Diethylene glycol succinate) with its packing materials (gas chromp. 100-120 mesh). The identification of fatty acid components from GLC analysis was carried out on the basis of relative retention time and was quantified by measuring the peak area in comparison with standard fatty acids. The fatty acids methyl ester mixture obtained from the lipids of $C$. batrachus were identified as oleic acid, lauric, palmitic, oleic, stearic acid, arachidic and behanic acid by comparison with standard methyl ester of fatty acids profile in different retention time where the areas under the peaks were proportional to the concentration of those components (Table 3).

The analytical data were summarized in the Table 3 . It was evident that the lipid of $C$. batrachus contained higher amount of oleic acid $(49.10 \%)$, palmitic acid $(37.41 \%)$, lauric acid $(2.60 \%)$ and stearic acid $(7.24 \%)$ of $P$. sutchi were lower than the lauric acid $(13.36 \%)$, stearic acid $(3.60 \%)$, arachidic 


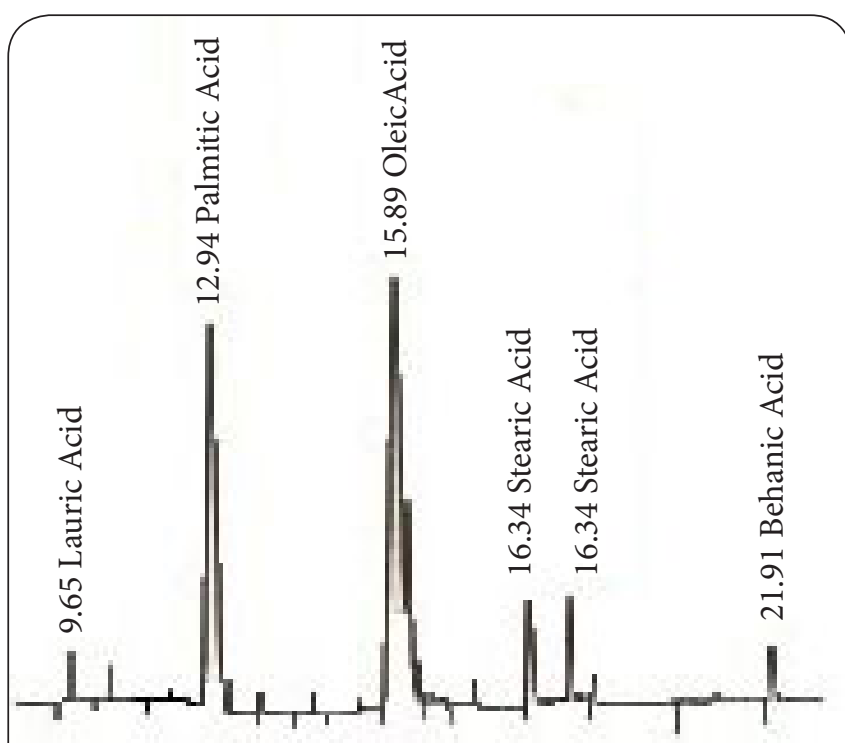

Figure 1. GLC Chromatogram of the fatty acid derived from methyl ester mixtures of Clarias batrachus.

Table 4. Fish fillet analysis of Clarias batrachus.

\begin{tabular}{lc}
\hline Name of composition & Clarias batrachus \\
\hline Moisture content & $78 \%$ \\
Dry matter content & $47.92 \%$ \\
Ash content & $0.1 \%$ \\
Carbohydrate content & $6.26 \%$ \\
Protein & $14.14 \%$ \\
\hline
\end{tabular}

Values are given as mean of triplicate experiments.

Table 5. Mineral content analysis of Clarias batrachus.

\begin{tabular}{ll}
\hline Name of minerals & Concentration in $(\mathrm{mg} / \mathrm{kg})$ \\
\hline Calcium & 210.10 \\
Phosphorous & 70.05 \\
Iron & 7.06 \\
Zinc & Traces amount \\
\hline
\end{tabular}

acid (3.04\%) and behanic acid (4.21\%). On the other hand, the previous report expressed that the predominant fatty acids in sardine wastes were palmitic (C16:0; $27.80-35.56 \%)$, stearic (C18:0; 5.90-9.30\%), oleic (C18:1; 15.47- 21.79\%) which have the similarities to our results [17] (Table 3).

The moisture contents of $C$. batrachus were tabulated in Table 4. The moisture content of C. batrachus was 78\%. The moisture of two species found in the present study was more or less similar to the result of $[\mathbf{1 8 , 1 9 ]}$. The ash contents of fishes were ranges $0.1 \%$. Besides, the percentages of dry matter contents of fishes are $47.92 \%$. The carbohydrate percentage of $C$. batrachus was $6.26 \%$. On the contrary, the previous research showed that the moisture, ash and protein content of Clarias batrachus (Magur) were 80.74, 0.95, and 15.22\% respectively [20].

\section{Nutritional status of Clarias batrachus}

The nutrients such as proteins are essential to all life. In animals, they help form supporting and protective structures such as cartilage, skin, nails, hair and muscles. They are major constituents of enzymes, antibodies, many hormones, and body fluids such as blood, milk and egg white [21]. Fishes contain higher amount of protein. However, the protein contents of $C$. batrachus (14.14\%) (Table 4).

Calcium is the most abundant mineral in the human body ( $2 \%$ of the body weight) and the fifth most abundant metallic element in the earth's crust. Calcium is essential for the growth, bone formation, blood coagulation, milk formation, vitamin $\mathrm{D}$, absorption, etc. It is an inert inorganic mineral usually associated with bones and tooth formation. Deficiency of calcium leads to rickets, osteomalacia and osteo porosis [22]. The total amount of calcium in the body is about $1200 \mathrm{~g}$. Calcium content of C. batrachus were $210.10 \mathrm{mg} / \mathrm{kg}$.

Phosphorous is a major constituent of all animal cells, phosphorous is present in allnatural foods. Primary dietary deficiency of phosphorous is not known to occur in man, though it may arise in cattle grazing on land lacking in phosphates. In people taking large quantities of aluminium hydroxide antacids dietary phosphate is bound and not absorbed. This can lead to secondary phosphate depletion. Occasionally cases have been reported. There are muscle weakness and bone pains. Plasma inorganic phosphate is very low and urinary phosphorous only about $15 \mathrm{mg} /$ day. Most of the phosphate in the body is present in bones which contain from 600 to $900 \mathrm{~g}$ P. Bone ash was a component of many ancient and mediaeval remedies and later glycerol phosphates have had a great vogue as a tonic. Now with all other tonics it is in disrepute. Phosphate metabolism may be disturbed in many types of disease, notably those affecting the kidneys and bones [23]. In this study, the C. batrachus contained higher amount of phosphorous ( $70.05 \mathrm{mg} / \mathrm{kg}$ ) (Table 5).

Iron is a macronutrient. It is in essential in life supporting element for animal and human being. All fishes are sufficient source of iron. The total iron content of the adult is about 4 to $5 \mathrm{~g}$. Iron plays an important role in cellular metabolism as an active component of various enzymes, especially those associate with the respiration chain of mitochondria. Iron function mainly in the transport of oxygen to the tissues (hemoglobin). It is also involved in the processes of cellular respiration. Iron deficiency anemia is widely prevalent among children, adolescent girls and nursing mothers [24]. In this study, the iron conc. of C. batrachus was $7.06 \mathrm{mg} / \mathrm{kg}$.

Zinc is also micronutrients. Zinc is essential element for animals, humans and plants. Although zinc represents only 0.003 percent of the human body, it is an intrinsic part of at least 110 metalloenzymes (alcohol dehydrogenate 
lactate dehydrogenate, glutamate dehydrogenate, carboxy peptidases A and B, carbonic anhydrate, etc.) and other cellular components. If is essential for synthesis of protein, RNA and DNA. Zinc helps in the transport of vitamin 'A'. Dietary zinc to copper ratio is important for disease increases. Zinc levels in the bloods decreases for two to three days after heart attack. Studies have shown that raising the blood level of zinc protects heart damage after a heart attack. The most prominent sings of zinc deficiency are growth retardation, anemia, and impaired sexual development, skin changes, loss of appetite, white opaque spots on finger nails [25]. In a C. batrachus the zinc contents were trace amounts.

\section{Conclusion}

The results obtained from this study suggested that lipids of Clarias batrachus are suitable for edible purpose as it contained higher amount of unsaturated fatty acids. These unsaturated fatty acids always play an important role in the metabolism of living organism. Moreover, fishes also contain higher amount of macro and micro nutrients which may take part in the buildup of human good health.

\section{Competing interests}

The authors declare that they have no competing interests.

Authors' contributions

\begin{tabular}{|l|c|c|c|c|c|c|}
\hline Authors' contributions & RI & LKM & LS & SSR & MI & AR \\
\hline Research concept and design & $\checkmark$ & $\checkmark$ & $\checkmark$ & $\checkmark$ & $\checkmark$ & $\checkmark$ \\
\hline Collection and/or assembly of data & $\checkmark$ & $\checkmark$ & $\checkmark$ & $\checkmark$ & $\checkmark$ & -- \\
\hline Data analysis and interpretation & $\checkmark$ & $\checkmark$ & $\checkmark$ & -- & -- & -- \\
\hline Writing the article & $\checkmark$ & -- & -- & $\checkmark$ & -- & $\checkmark$ \\
\hline Critical revision of the article & $\checkmark$ & -- & -- & -- & -- & $\checkmark$ \\
\hline Final approval of article & $\checkmark$ & -- & -- & -- & -- & $\checkmark$ \\
\hline Statistical analysis & $\checkmark$ & -- & -- & -- & -- & -- \\
\hline Research Supervision & $\checkmark$ & -- & -- & -- & -- & - \\
\hline
\end{tabular}

\section{Acknowledgement}

This research project was supported by the Faculty of Science \& Technology, Islamic University, Kushtia, Bangladesh. Besides, we are grateful to Organic Chemistry Laboratory, University of Dhaka for supporting GLC analysis.

\section{Publication history}

Editors: L Preston Mercer, University of South Florida, USA. Ana Raimunda Dâmaso, Federal University of São Paulo, Brazil. Received: 17-Aug -2013 Revised: 22-Sep-2013

Accepted: 27-Sep-2013 Published: 10-Oct-2013

\section{References}

1. M. Mustafa, MD. A Rashid, Z. Ferdous, M. S. Alam, R. Ara Begum and Reza MD Shahjahan. Tissue specific esterase isozyme variation in four punctius species. 2013; 1:254-259. | Pdf

2. K.C. Jayaram. The Freshwater Fishes of India, Pakistan, Bangladesh, Burma, and Sri Lanka- A Handbook. Zoological Survey of India, Calcutta. 475, 1981.
3. P.K. Talwar and A.G. Jhingran. Island fishes of India and adjacent countries. A.A. Balkema, Rotterdam, Netherlands. 1992.

4. S. Debnath. Clarias batrachus, the medicinal fish: An excellent candidate for aquaculture \& employment generation. International Conference on Asia Agriculture and Animal IPCBEE, Singapoore, 2011; 13:32-37. I Pdf

5. C.M.O. Alexandra and J. B. Peter. Characterization of live lipid and protein from cold-water fish species. J. Food Sci. 2006; 71:480-485.

6. A. S. M. Musa. National quality components of indigenous freshwater fish species, puntius stigma in Bangladesh. Bangladesh J. Sci. Ind. Res. 2009; 44:367-370. I Pdf

7. H.A. Bockenoogen. Analysis and characterization of oil, fats and fat products. 1(27):211-223, 1964.

8. M.A. Loury. General method for rapid conversion of fats to methyl esters. Revue Franc. Corps. Gras. 14(6):383-387, 1967.

9. K. Randerath. Thin layer chromatography. Academic Press, New York. 21(5), 235, 1966.

10. T. Pervin, S. Yeasmin, R. Islam, Kamruzzaman, A. Rahman and A. Sattar. Studies on nutritional composition and characterization of lipids of Lates calcarifer (Bhetki). Bangladesh J. Sci. Ind. Res. 2012; 47:393-400. I Pdf

11. J.M. Clark. Experimental biochemistry, W.H. Freeman and Company. USA. 52. 1964.

12. M. E. Stansby. Analytical methods on industrial fishery technology. Rhenhold Publishing Corporation. New York. 369-370, 1963.

13. A. Suloma and H.Y. Ogata. Lipid and Fatty Acid Composition of Commercially Important Tropical Freshwater Fish Gonads:Guidelines for Specific Broodstock Diet. J. Fish. Aquat. Sci. 12:743-749. 2012. | Pdf

14. A. Giausuddin, S. Yearul, J. Syeda. Effect of Hilsa Ilisha fish oil, soybean and palm oil on the serum and liver lipids of experimentally-induced hypercholesterolemic rats. Pak. J. Med. Res., 2006; 45:53-58. | Article

15. A.H. Molla, S. Camellia, M.S. Ahsan, S.M. Talukder, Alam MT Physicochemical and microbiological investigation of the lipid from Bangladeshi fresh water fish Mystus vittatus. Univ. j. zool. Rajshahi Univ.2007; 26:21-25. | Article

16. R. Islam, D.K. Paul, A. Rahman, T. Parvin, D. Islam and A. Sattar. Comparative characterization of lipids and nutrient contents of Pangsius pangsius and Pangsius sutchi available in Bangladesh. J. Nutr. \& Food Sci., 2012; 2:130. | Article

17. A. Khoddami, A.A. Ariffin, J. Bakar, and H.M Ghazali. Fatty Acid Profile of the Oil Extracted from Fish Waste (Head, Intestine and Liver) (Sardinella lemuru). World App. Sci. J. 2009; 7:127-131. | Pdf

18. D. Kamal , A.N. Khan, M.A. Rahman and F. Ahamed. Biochemical composition of some small indigenous fresh water fishes from the River Mouri, Khulna, Bangladesh. Pak J Biol Sci. 2007; 10:1559-61. | PubMed

19. M.S. Islam, M.T. Molla, M. T. Alam and M.R. Habib. Physico-chemical behaviour of the fish lipid from Lepidocephalus guntea (Hamilton) and variation of lipid profile with size. Pak J Biol Sci. 2008; 11:1342-7. | PubMed

20. A. Shamim, A.F.M. A. Rahman, M.G. Mustafa,M. B. Hossain and N. Nahar. Nutrient Composition of Indigenous and Exotic Fishes of Rainfed Waterlogged Paddy Fields in Lakshmipur, Bangladesh. World J. Zool., 2012; 7:135-140. | Pdf

21. N.N. Potter and J. H. Hotchkiss. Food Science, (5th ed.), CBS Publishers \& Distributors, New Delhi, India. 30-32, 1996.

22. Anderson L. Nutrition in health and diseases. 17th ed. J. B. Lippicopp Company, Toronto, 1982.

23. A. Rosenquist and G. Holmer. Nutritional value of micro-encapsulated fish oils in rats. Z Ernahrungswiss. 1996; 35:178-84. | Article | PubMed

24. C.K. Gehring, J.C, Gigliotti, J.S. Moritz, J.C. Tou and J, Jaczynski. Functional and nutritional characteristics of proteins and lipids recovered by isoelectric processing of fish by-products and low value fish. J. Food Chem. 2011; 124(2):422-431. | Article

25. A.H. Molla. Biochemical and nutritional studies of the Bangladeshi 
Islam et al. Nutritional Science and Food Technology 2013,

http://www.hoajonline.com/journals/pdf/2054-1848-1-1.pdf

fresh water Eel, Anguilla Bengalensis (Bao Baim), A PhD. Thesis, submitted to the University of Rajshahi, 1991.

\section{Citation:}

Islam R, Mondol LK, Sheikh L, Rahman SS, Islam M and Rahman A. Identification of fatty acid profile, lipid characterization and nutritional status of Clarias batrachus. Nutr Sci Food Technol. 2013; 1:1.

http://dx.doi.org/10.7243/2054-1848-1-1 